\title{
Radio Resistance Mechanisms of Cancers: An Overview and Future Perspectives
}

Tai-Sheng Wu, Been-Ren Lin, Hao-Hueng Chang and Cheng-Chi Chang*

National Taiwan University, Taipei, Taiwan

\begin{abstract}
Radiation therapy is widely applied as a standard curative treatment in cancers and the therapeutic techniques have improved remarkably in recent years. However, repopulation of surviving cancer cells is frequently observed during fractionated radiotherapy, which limits the efficacy of radiotherapy. These surviving cells often acquire radio resistance through the deregulation of survival signaling pathways, DNA damage repair mechanisms, post-transcriptional regulation of miRNAs, and epigenetic modifications. Therefore, advances in our understanding of the mechanisms underlying cellular sensitivity to irradiation may provide novel diagnostic markers and therapeutic targets to improve the efficacy of radiotherapy. In this review, we summarize previous studies that report on the radio resistance of various cancer cells.
\end{abstract}

Keywords: Radiotherapy; Radio resistance; DNA damage repair; miRNA; Cancer stem cell; Epigenetic modification

\section{Introduction}

Radiotherapy (RT) is the standard curative treatment for a number of malignant tumors. At the beginning of the $20^{\text {th }}$ century, radium began to be used in cancer treatment via direct insertion into body cavities. However, the surrounding normal tissue was also injured from ionizing radiation (IR) exposure. With advances in computer technology, radiology developed computed tomography (CT), positron emission tomography (PET), and magnetic resonance imaging (MRI) scans to precisely map targeted tumors in order to reduce the damage to normal tissue. Nowadays, intensity-modulated radiation therapy (IMRT) and proton beam therapy are applied, by aiming photon and proton beams in several directions to efficiently eliminate tumors and to minimize injury to normal organs, which can withstand the treatment and recover after RT. However, despite the improvement of therapeutic techniques, numerous patients are prone to relapse due to the intrinsic resistance of cancer cells to radiation. It is important to uncover the underlying mechanisms and develop new strategies to solve this issue. Radio resistance may arise from a deregulated signaling pathway (e.g., AKT or $\mathrm{NF}-/ \beta$ - B), oncogenic miRNA overproduction, abnormal DNA damage response (Figure 1), or a particular epigenetic modification in cancer subpopulations, such as cancer stem cells (CSCs). Moreover, small populations of cancer cells may survive after RT and repopulate with advanced malignant phenotypes. In this review, we have summarized previous studies that reported on the radio resistance of various cancer cells.

\section{Signaling Pathways Response to RT}

Many survival signaling pathways such as the PI3K/AKT signaling pathway are activated after ionizing radiation (IR)-induced damage to protect cells from death. The DNA damage response is induced by the activation of specific sensors and causes cell cycle arrest; DNA repair processes, including single- and double-strand break repair (SSB and DSB repair), participate in and restore the damaged sites. Here, we briefly introduce crucial signaling pathways response to RT, including $\mathrm{PI} 3 \mathrm{~K} / \mathrm{AKT}$ and NF- $\kappa \mathrm{B}$, and the role of the DNA damage repair system in cancer cell radio resistance.

\section{PI3K/AKT signaling pathway}

PI3K/AKT activation is one of the most frequent events in multiple tumor types and regulates many cellular processes, including proliferation, invasion, apoptosis, and radio resistance [1-4]. The pathway also contributes to cancer-inducing tumor microenvironments, such as angiogenesis and recruitment of inflammatory cells $[5,6]$. The pathway is activated by upstream receptor tyrosine kinases (RTK), integrins, cytokine receptors, and G-protein-coupled receptors

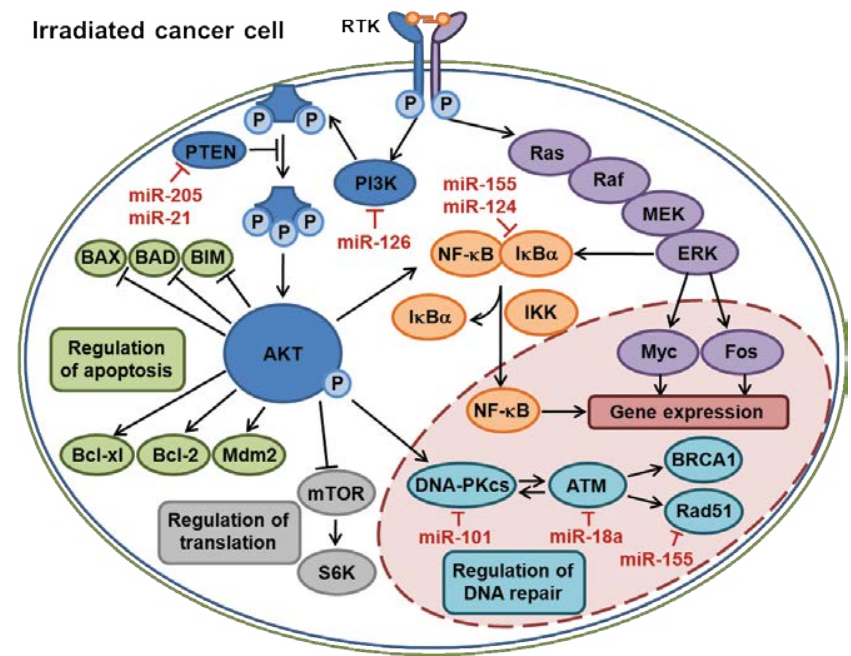

Figure 1: Intrinsic mechanisms regulate radiosensitivity and contribute radioresistant phenotype. $\mathrm{PI} 3 \mathrm{~K} / \mathrm{AKT}$ and MAPK/NF-KB regulates several cellular functions including apoptosis, DNA repair, transcription, and translation, all of which can be deregulated in radioresistant cancer cells. miRNA is also involved in the regulation of radioation related signaling pathways. A number of miRNAs could modulate the expression of key components in PI3K/AKT and MAPK/NF-KB pathways, and further influence the radiosensitivity of cancer cells. Arrows represent activation; bars represent inhibition.

*Corresponding author: Cheng-Chi Chang, National Taiwan University, Taipei, Taiwan, Tel: +886 23366 33; E-mail: ccclrc@gmail.com

Received March 20, 2015; Accepted April 29, 2015; Published May 06, 2015

Citation: Wu TS, Lin BR, Chang HH, Chang CC (2015) Radio Resistance Mechanisms of Cancers: An Overview and Future Perspectives. Biol Med S2: 002 doi: 10.4172/0974-8369.S2-003

Copyright: (c) 2015 Wu TS, et al. This is an open-access article distributed under the terms of the Creative Commons Attribution License, which permits unrestricted use, distribution, and reproduction in any medium, provided the original author and source are credited. 
(GPCR), which are frequently dysregulated in cancer [7]. PI3K also acts as a central node to transmitted signals by phosphorylates Akt. Akt is the crucial mediator that phosphorylates several downstream targets and promotes cancer progression. These include negative regulation of a pro-apoptotic protein such as $\mathrm{BAD}[8]$ and positive regulation of pro-survival genes such as HIF-1 $\alpha$ and VEGF $[9,10]$ to prevent cell death and promote cancer growth and metastasis. In response to IRinduced DDR, PI3K activated by RTKs leads to phosphorylation of $\mathrm{AKT}$ and subsequently induces downstream effectors (such as Bcl2 and mTOR) to influence cell radiosensitivity. For instance, it was discovered that EGFRvIII, an epidermal growth factor receptor, could confer radio resistance in glioblastoma multiforme through activated PI3K/AKT signaling and accelerated DSB repair by DNA-dependent protein kinase catalytic subunit (DNA-PKcs) activation [11]. Moreover, preclinical data indicated that the anti-EGFR agent cetuximab was a radio sensitizer in pancreatic cancer. Combining cetuximab with RT achieved excellent local control with minimal toxicity in pancreatic cancer patients [12]. Furthermore, it has been demonstrated that the synergism between IR and a PI3K inhibitor BKM120 inhibits the activation of Akt by IR, leading to a reduction in DSB repair and promotion of cell apoptosis in hepato cellular carcinoma cells [13]. These findings suggest a new therapeutic strategy for radio sensitizing the PI3K/AKT inhibitor treatment.

\section{NF-кB signaling pathway}

The NF- $\kappa B$ family of transcription factors is involved in the regulation of a wide variety of biological responses. Mammalian cells express five NF- $\kappa B$ genes, including NF- $\kappa \mathrm{B} 1, \mathrm{NF}-\kappa \mathrm{B} 2$, RelA, RelB, and $\mathrm{c}-\mathrm{Rel}$, that share a highly conserved $\mathrm{N}$-terminal domain called the Rel homology domain (RHD), which mediates their dimerization, interaction with their specific inhibitors, and DNA binding [14]. The NF-kB complex is activated in response to a variety of stimuli, including cytokines, growth factors, RTKs, and stress-inducing agents such as reactive oxygen species (ROS) $[15,16]$. NF- $\kappa B$ plays a well-known role in immune response and inflammation regulation, and is increasing recognized as a crucial player in cancer progression by inducing cell invasion, migration, and proliferation. Moreover, NF- $\kappa \mathrm{B}$ acts as a stresssensitive hetero dimeric transcription factor that regulates numerous stress responsive factors, including the IR damage response. Once NF- $\kappa B$ initiates prosurvival signaling pathways after RT, it not only promotes radio resistance but also increases the malignant potential of repopulation tumors. For example, it has been demonstrated that MET, a member of the RTK family, was over expressed and phosphorylated in the absence of its ligand HGF after IR. NF- $\mathrm{kB}$ was an inducer that directly targeted the MET promoter to increase its expression, which consequently reduced cell apoptosis and promoted proliferation in irradiated cells [17]. Furthermore, NF- $\kappa$ B-induced MET expression strongly increased cell invasion and enhanced tumor relapse after irradiation therapy. Taken together, NF- $\kappa$ B signaling may cause radioresistance in $\mathrm{RT}$-treated cancer cells.

\section{Double-strand break repair}

DSB is one of the most important DNA damages induced by IR, and today, much evidence has confirmed and intensified the correlation between DSB repair and radio resistance. Two repair mechanisms are involved in DSB, homologous recombination (HR) and nonhomologous end joining (NHEJ), that differ in their fidelity and template requirements.

\section{Homologous recombination}

HR is predominant in the $\mathrm{S}$ and G2 phases because of the proximity of the homologous template. Recently, studies have discovered that IR-induced DSB activates different damage sensors, such as ataxia telangiectasia mutated (ATM) and BRCA1, that recruit DNA repair complexes to proceeding damage recovery [18-20]. For example, radio resistant subpopulations of breast cancer cells exhibited hyperactivated ATM. Phosphorylated ATM stabilized the interaction between ZEB1 and USP7 to deubiquitylate CHK1, which induced HR and contributed to a radio resistant phenotype [21]. Moreover, glioblastoma CSCs displayed up-regulated phosphorylated DNA damage response proteins and induced G2/M checkpoint activation following IR. Inhibition of ATM kinase by KU-55933 produced potent radiosensitization of the glioblastoma CSCs and effectively abrogated the DSB repair system [22]. Inhibition of ATM-Rad3-related (ATR) by VE-821also led to the abolition of IR-induced G2/M arrest, which further increased DNA damage and inhibition of HR repair in pancreatic cancer cells [23]. In addition, Shelton JW et al demonstrated that combining RT with a PARP inhibitor, ABT-888 significantly reduced clonogenic ability in vitro and tumor growth in vivo of colorectal cancer cells by impairing the DSB repair system. These findings suggest that combining RT with crucial DSB repair molecular inhibitors may be a novel approach to improve RT therapy.

\section{Non-homologous end joining}

NHEJ plays major roles in cell cycle $\mathrm{S}$ and $\mathrm{M}$ phases by directly recovering the damage sites without the need for a homologous template. Hyper activation of NHEJ imparts radio resistance in many cancer types, including esophageal squamous cell carcinoma, prostate cancer, glioblastoma, lung cancer, cervical cancer, and oral squamous cell carcinoma [24-29]. Beskow et al. [28] analyzed DNA-PKcs, Ku70, and Ku86 expression in 22 samples from cervical cancer patients treated with RT followed by residual tumors, found that relapse tumors represented a higher expression of those NHEJ factors compared with primary tumors. These data suggest that over expression of NHEJ factors may dictate DSB repair and restore the tumor populations in cancers.

\section{Microrna System Response To Radiotherapy}

MicroRNAs (miRNAs) are small (19-25 nucleotide), noncoding RNA molecules that negatively regulate gene expression by base pairing with 3 '-untranslated regions (3'-UTRs) of target mRNAs leading to translational suppression or degradation [30]. Studies have shown that miRNAs play an important role in physiological processes such as proliferation, development, differentiation, metabolism, and the immune system [31-33]. Accumulation evidence suggests that miRNAs emerged as important players in tumorigenesis, acting as oncogenes or tumor suppressors depending on their cancer-related target genes [34]. For example, dysregulation of miRNA cluster miR-17-92 was found in many cancer types, including small-cell lung cancer, retinoblastoma, and oral cancer [35-37]. Kandalam et al. [36] demonstrated that EpCAM regulates the miR 17-92 cluster expression that further influences cell proliferation and invasion in retinoblastoma cells, and when transfected with antagomirs significantly decreased cell viability and induced cell apoptosis. Interestingly, Chang et al. [37] found that miR-17/20a, two members of the miR-17-92 cluster, represented a negative correlation with TNM and lymphatic metastasis clinically, and over expression of miR17/20a significantly decreased the migratory ability of oral cancer cells by directly targeting $3^{\prime}$-UTR of integrin $\beta 8$. These findings indicated that the same miRNA may play opposite roles in different cancers, and further discovery of miRNA targets and their relevant pathways are urgently needed. Recently, many studies have observed 
that dysregulation of these miRNAs may influence radiosensitivity in cancers. We summarize the role of miRNAs on radio sensitivity in various types of cancers that use RT as a standard therapy in Table 1. Numerous studies have identified that some miRNAs could act as "radio sensitizers" to strengthen the radio response of cancer cells and may serve as therapeutic targets [38-51]. Those miRNAs are involved in several radiobiological mechanisms, including DNA damage response, autophagy, and survival pathway alterations. For example, Zhang et al. [47] found that miR-205 inhibited DNA damage repair by targeting ZEB1 and Ubc13 in response to IR, and a loss of miR-205 was associated with poor survival of breast cancer patients. Conversely, it has been demonstrated that miR-205 contributed to a radioresistant phenotype by targeting PTEN, and further activated the AKT signaling pathway against IR-induced cell apoptosis in nasopharyngeal carcinoma [52]. That miRNAs cause radioresistance when overexpressed in cancer cells has also been extensively studied in varous cancer types [53-57]. Many interesting reports provide evidence that different miRNAs affect the radioresponse through their downstream machinery. However, these outcomes may not reflect true radiosensitivity, and clinical validation for those miRNAs on their radioreponse is currently lacking and needs further investigation.

\section{Epigenetic Modification In Radiotherapy}

Epigenetic alterations, including DNA methylation, histone modification, and chromatin remodeling are crucial to regulate cell phenotypes without a corresponding change in the DNA sequence. In human cancers, these epigenetic abnormalities affect many neoplasm processes by regulating tumor-suppressor genes or oncogenes. Increasing evidence indicates that epigenetic alternations can regulate radiosensitivity by interfering with DNA repair, cell cycles, programmed cell death, and cancer stemness properties [58-62], there by emerging as potential therapeutic targets.

\section{DNA methylation}

DNA methylation is one of the most common and most extensively studied epigenetic modifications in many types of cancers, including prostate, glioma, lung, liver, colon, and breast cancers [63-67]. However, a relatively small number of studies have focused on how DNA methylation changes cause cancer cell radio resistance. An analysis of global $\mathrm{CpG}$ methylation profiles of radiosensitive $\mathrm{H} 460$ and radio resistant H1299 non-small cell lung cancer cell lines by microarray analysis revealed that 747 genes were hypermethylated and 344 genes were hypomethylated in promoter CpG sites [68] Among the hypermethylated genes, SERPINB5 and S100A6 were highly expressed in the radiosensitive cell line, and repression of these two genes by siRNA could significantly reduce cell death from IR. In contrast, catalase (CAT) and basonuclin 1 (BNC1), hypomethylated in promoter $\mathrm{CpG}$ sites, were highly expressed in radio resistant cells. Down-regulation of these two genes also increased the radio sensitivity of H1299 cells, emphasizing the important role of CpG methylation of crucial genes in radiosensitivity regulation.

\section{Histone modification}

In addition to DNA methylation, the structure of chromatin can be remodeled by histones that play important roles in gene expression regulation. Translational modifications of histones, such as methylation and acetylation, are through site-specific modifiers, including histone methyltransferase (HMT), histone acetyltransferase (HAT), histone deacetylase (HDAC), and ADP-ribosylatioin. Many studies have observed that dysregulation of these modifiers may contribute to cancer progression and therapy failure.

\begin{tabular}{|c|c|c|c|c|c|}
\hline Tumor Types & miRNAs & Targets & Functions & RT sensitivity & References \\
\hline Nasopharyngeal & $\operatorname{miR}-24$ & $\mathrm{H} 2 \mathrm{AX}$ & Inhibit DNA damage repair & $\uparrow$ & [38] \\
\hline \multirow{6}{*}{ Esophageal } & miR-185-3p miR-324-3p & WNT2B & $\begin{array}{l}\text { Inhibit WNT signaling } \\
\text { pathway }\end{array}$ & $\uparrow$ & {$[39,40]$} \\
\hline & miR-451 & RAB14 & Inhibit DSBs repair & $\uparrow$ & [41] \\
\hline & miR-205 & PTEN & Induce AKT activation & $\downarrow$ & [52] \\
\hline & miR-381 & - & $\begin{array}{l}\text { Reduce cell proliferation } \\
\text { and migration }\end{array}$ & $\uparrow$ & [42] \\
\hline & $\mathrm{miR}-21$ & - & Induce AKT activation & $\downarrow$ & [53] \\
\hline & miR-31 & - & $\begin{array}{c}\text { Reduce DNA repair genes } \\
\text { expression }\end{array}$ & $\uparrow$ & [43] \\
\hline \multirow[t]{6}{*}{ Lung } & $\mathrm{miR}-15 \mathrm{a} / 16$ & TLR1 & Inhibit activation of NF-kB & $\uparrow$ & [44] \\
\hline & miR-511 & TRIB2 & Induce cell apoptosis & $\uparrow$ & [45] \\
\hline & miR-34a & $\mathrm{NOTCH} 1$ & Inhibit activation of NF-KB & $\uparrow$ & [46] \\
\hline & & NDFUA4 & \multirow{2}{*}{ Promote DSBs repair } & \multirow{2}{*}{$\downarrow$} & \multirow{2}{*}{ [54] } \\
\hline & mIR-210 & SDHD & & & \\
\hline & miR-21 & PTEN & $\begin{array}{l}\text { Induce cell proliferation } \\
\text { and migration }\end{array}$ & $\downarrow$ & [55] \\
\hline \multirow{5}{*}{ Breast } & & ZEB1 & \multirow{2}{*}{ Inhibit DNA damage repair } & \multirow{2}{*}{$\uparrow$} & \multirow{2}{*}{ [47] } \\
\hline & miR-20s & Ubc13 & & & \\
\hline & $\mathrm{miR}-200 \mathrm{c}$ & UBQLN1 & Inhibit autophagy & $\uparrow$ & [48] \\
\hline & miR-155 & RAD51 & $\begin{array}{l}\text { Impair homologous } \\
\text { recombination }\end{array}$ & $\uparrow$ & [49] \\
\hline & miR-95 & SGPP1 & Induce S1P signaling & $\downarrow$ & [56] \\
\hline Pancreas & miR-23b & ATG12 & Inhibit autophagy & $\uparrow$ & [50] \\
\hline \multirow[t]{3}{*}{ Rectum } & miR-124 & PRRX1 & Induce cell apoptosis & $\uparrow$ & [51] \\
\hline & \multirow{2}{*}{ miR-21 } & TP & \multirow{2}{*}{$\begin{array}{l}\text { Induce cell proliferation } \\
\text { and reduce apoptosis }\end{array}$} & \multirow{2}{*}{$\downarrow$} & \multirow{2}{*}{ [57] } \\
\hline & & DPD & & & \\
\hline
\end{tabular}

Table 1: The role of miRNAs in radiosensitivity regulations in different cancer types. 


\section{Histone methylation}

Depending on the different target sites, methylation or demethylation of histone could promote or prevent transcriptional activity [69]. Histones can be methylated on residues of lysine (K) and arginine (R). Methylation of lysine residues of histone 3 is the most common, including $\mathrm{K} 4, \mathrm{~K} 9, \mathrm{~K} 27, \mathrm{~K} 36, \mathrm{~K} 48$, and $\mathrm{K} 79$, which regulates gene expression by mono-methylation, di-methylation, and tri-methylation. Common sites associated with methylation for gene activation are $\mathrm{H} 3 \mathrm{~K} 4, \mathrm{H} 3 \mathrm{~K} 48$, and $\mathrm{H} 3 \mathrm{~K} 79$, and sites associated with gene repression are $\mathrm{H} 3 \mathrm{~K} 9$ and $\mathrm{H} 3 \mathrm{~K} 27$. It has been demonstrated that enhancement of the zeste homolog 2 (EZH2), a HMT that catalyzes H3K27 methylation, was highly expressed in post irradiation recurrent glioblastoma. Its expression was negatively correlated with clinical patient prognosis [70]. Furthermore, attenuated EZH2 activity by treatment with the EZH2 inhibitor significantly restored IR-induced apoptotic populations in radio resistant glioblastoma cells. Interestingly, EZH2 over expression was also associated with malignancy and poor prognosis of a variety of cancers, including lung, breast, prostate, lymphoma, gastric, hepatic, and head and neck squamous cell carcinoma [71-76]. Those results indicated that histone methylation not only contributes to a radioresistant phenotype, but also affects malignant behavior by influencing gene expression in cancers.

\section{Histone acetylation and deacetylation}

Many reports have demonstrated a significant correlation between histone acetylation and cancer progression [77,78]. Dysregulation of acetylation and deacetylation by HAT and HDAC is coupled to initiation and progress in cancers. Inhibition of HDACs has been preclinically and clinically proven to overcome radio-and chemoresistance of tumors. For instance, vorinostat, a specific HDAC inhibitor, radiosensitized neuroblastoma cells in vitro and in vivo by down-regulation of the DNA repair enzyme Ku-86 [79]. Clinically, vorinostat is the most advanced HDAC inhibitor to have entered clinical trials in cancers, including glioblastoma and gastrointestinal carcinoma [80,81]. However, it showed only modest benefits and it still needs to be confirmed in larger prospective trials.

\section{Cancer Stem Cell Population Response To Radiotherapy}

CSCs are defined as a small population within a tumor that possesses the capacity to self-renew and to generate the heterogeneous lineages of cancer cells [82]. This definition implies that cancer can only be cured if all CSCs are eliminated by anticancer therapy. There is increasing evidence that these CSCs are resistant to radiation therapy, and this property contributes to the poor therapeutic outcome of cancer patients $[83,84]$. For example, CD133-positive glioblastoma (GBM) cells, considered to be CSCs, presented high tumorigenic and radio resistant properties with strong STAT3 phosphorylation [85]. Treatment of GBM-CD $133^{+}$cells with the STAT3 inhibitor suppressed stemness gene expression and facilitated the differentiation of GBM$\mathrm{CD}_{133^{+}}$cells into GBM-CD133-cells. Therefore, inhibiting STAT3 signaling could induce apoptosis and radiosensitivity. A similar result was also observed in HNSCC [86]. Chen et al. [86] demonstrated that CD44, ALDH1, and phosphorylated STAT3 were highly expressed in high-grade HNSCCs, and $\mathrm{CD} 44^{+} \mathrm{ALDH}^{-}$cells displayed greater tumorigenicity, sphere formation ability, radio resistance and epithelial- mesenchymal-transition. Notably, xenotransplant animal experiments showed that a STAT3 inhibitor combined with RT significantly reduced tumorigenesis and metastasis, and emerged as a potential radio sensitizer in anti-CSC therapy. In addition to STAT3 signaling, numerous studies have shown that CSCs can be protected by many intrinsic and extrinsic mechanisms, including enhanced DNA repair, activation of survival signaling pathways (such as PI3K/ $\mathrm{AKT}$ and $\mathrm{WNT} / \beta$ - catenin), and tumor microenvironments (e.g., growth factors and cytokines) [22, 87-92]. It was also discovered that subsets of CSCs in some human and murine breast tumors contained lower ROS levels than corresponding non-tumorigenic cells. CSCs in these tumors generated less DNA damage after irradiation because of their high expression levels of free radical scavenging systems. Treatment with a ROS scavenger inhibitor significantly decreased CSCs clonogenicity and resulted in radio sensitization [93]. Furthermore, it was also found that breast CSCs (BCSCs) expressed high levels of a free radical scavenger, a phenomenon HAT was independent of hypoxia and was maintained when cells were re-oxygenated [94]. Since then, a number of experimental studies and clinical research have focused on the improvement of loco-regional control after IR treatment through correction of tumor hypoxia; this study may explain why correcting hypoxia has not significantly improved clinical outcomes. The emerging knowledge suggests that targeting CSCs is a potential therapeutic strategy to overcome radio resistance after RT.

\section{Summary and Future Directions}

Tumor biology has developed over decades and significant improvements to cancer therapies have increased patients' life spans. $\mathrm{RT}$ is an effective approach for local tumor control. However, resistance to irradiation remains one of the major hurdles for successful control of the disease. The radio response of a tumor is the key factor in determining the therapeutic effect, which is related to tumor radio sensitivity and radio resistance. Several biological processes are involved in radio response regulation, including activation of survival signaling pathways, DNA damage responses and repair mechanisms, miRNA regulation, and epigenetic modification. Our summaries here demonstrated that some classical pathways played important roles in modulating the radio response, particularly PI3K/AKT and NF$\kappa \mathrm{B}$ pathways. MiRNA is a class of short, non-coding ribonucleic acid molecules that influenced tumor metastasis and radio resistance. We highlighted the crucial miRNAs in radio sensitivity regulation through the post-transcriptional repression of target genes to control DNA damage repair, survival, autophagy, or apoptosis. DNA methylation and histone modification also played important roles in the dynamic processes of a tumor acquiring a radio resistant phenotype. The parallel growth in our understanding of genetics and epigenetics may provide novel diagnostic markers and therapeutic targets to improve the efficacy of RT. Moreover, much evidence indicated that CSCs have the capacity to regenerate heterogeneous cell populations after IR and generate radio resistance. Uncovering the intrinsic and extrinsic mechanisms that control the maintenance of CSCs is crucial for developing novel therapeutic strategies to eliminate CSCs, and further eradicate cancers without apparent recurrence in the future.

\section{References}

1. Shimura T, Noma N, Oikawa T, Ochiai Y, Kakuda S, et al. (2012) Activation of the AKT/cyclin D1/Cdk4 survival signaling pathway in radioresistant cancer stem cells. Oncogenesis 1: e12.

2. Minjgee M, Toulany M, Kehlbach R, Giehl K, Rodemann HP (2011) K-RAS(V12) induces autocrine production of EGFR ligands and mediates radioresistance through EGFR-dependent Akt signaling and activation of DNA-PKcs. Int J Radiat Oncol Biol Phys 81: 1506-1514.

3. Shimura T, Kakuda S, Ochiai $Y$, Nakagawa H, Kuwahara $Y$, et al. (2010) Acquired radioresistance of human tumor cells by DNA-PK/AKT/GSK3betamediated cyclin D1 overexpression. Oncogene 29: 4826-4837.

4. Golding SE, Morgan RN, Adams BR, Hawkins AJ, Povirk LF, et al. (2009) Prosurvival AKT and ERK signaling from EGFR and mutant EGFRvIll enhances 
DNA double-strand break repair in human glioma cells. Cancer BiolTher 8: 730-738.

5. Zhang J, Yu XH, Yan YG, Wang C, Wang WJ (2015) PI3K/Akt signaling in osteosarcoma. ClinChimActa 444: 182-192.

6. Zhang $\mathrm{Y}$, Wang L, Zhang M, Jin M, Bai C, et al. (2012) Potential mechanism of interleukin-8 production from lung cancer cells: an involvement of EGF-EGFRPI3K-Akt-Erk pathway. J Cell Physiol 227: 35-43.

7. Engelman JA, Luo J, Cantley LC (2006) The evolution of phosphatidylinositol 3-kinases as regulators of growth and metabolism. Nat Rev Genet 7: 606-619.

8. Zhao S, Konopleva M, Cabreira-Hansen M, Xie Z, Hu W, et al. (2004) Inhibition of phosphatidylinositol 3-kinase dephosphorylates BAD and promotes apoptosis in myeloid leukemias. Leukemia 18: 267-275.

9. Koshikawa NJ, Hayashi A, Nakagawara K, Takenaga (2009) Reactive oxygen species-generating mitochondrial DNA mutation up-regulates hypoxia-inducible factor-1alpha gene transcription via phosphatidylinositol 3-kinase-Akt/protein kinase C/histone deacetylase pathway. J Biol Chem 284 33185-33194.

10. Ma J, Sawai H, Ochi N, Matsuo Y, Xu D, et al. (2009) PTEN regulates angiogenesis through PI3K/Akt/VEGF signaling pathway in human pancreatic cancer cells. Mol Cell Biochem 331: 161-171.

11. Mukherjee B, McEllin B, Camacho CV, Tomimatsu N, Sirasanagandala S, et al (2009) EGFRvIII and DNA double-strand break repair: a molecular mechanism for radioresistance in glioblastoma. Cancer Res 69: 4252-4259.

12. Rembielak AIP, Jain AS, Jackson MM, Green GR, Santorelli, et al. (2014) Phase II Trial of Cetuximab and Conformal Radiotherapy Only in Locally Advanced Pancreatic Cancer with Concurrent Tissue Sampling Feasibility Study. Trans Oncol 7: 55-64.

13. Liu WL, Gao M, Tzen KY, Tsai CL, Hsu FM, et al. (2014) Targeting Phosphatidylinositide3-Kinase/Akt pathway by BKM120 for radiosensitization in hepatocellular carcinoma. Oncotarget 5: 3662-3672.

14. Ghosh S, May MJ, Kopp EB (1998) NF-kappa B and Rel proteins: evolutionarily conserved mediators of immune responses. Annu Rev Immunol 16: 225-260.

15. Bonizzi G, Karin M (2004) The two NF-kappaB activation pathways and their role in innate and adaptive immunity. Trends Immunol 25: 280-288.

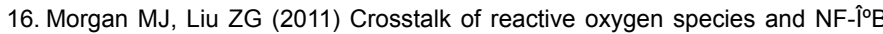
signaling. Cell Res 21: 103-115.

17. De Bacco F, Luraghi P, Medico E, Reato G, Girolami F, et al. (2011) Induction of MET by ionizing radiation and its role in radioresistance and invasive growth of cancer. J Natl Cancer Inst 103: 645-661.

18. Lim YC, Roberts TL, Day BW, Stringer BW, Kozlov S, et al. (2014) Increased sensitivity to ionizing radiation by targeting the homologous recombination pathway in glioma initiating cells. MolOncol 8: 1603-1615.

19. Brett-Morris A, Wright BM, Seo Y, Pasupuleti V, Zhang J, et al. (2014) The polyamine catabolic enzyme SAT1 modulates tumorigenesis and radiation response in GBM. Cancer Res 74: 6925-6934.

20. Li W, Katoh H, Wang L, Yu X, Du Z, et al. (2013) FOXP3 regulates sensitivity of cancer cells to irradiation by transcriptional repression of BRCA1. Cancer Res 73: 2170-2180.

21. Zhang P, Wei Y, Wang L, Debeb BG, Yuan Y, et al. (2014) ATM-mediated stabilization of ZEB1 promotes DNA damage response and radioresistance through CHK1. Nat Cell Biol 16: 864-875.

22. Carruthers R, Ahmed SU, Strathdee K, Gomez-Roman N, Amoah-Buahin E, et al. (2015) Abrogation of radioresistance in glioblastoma stem-like cells by inhibition of ATM kinase. MolOncol 9: 192-203.

23. Prevo R, Fokas E, Reaper PM, Charlton PA, Pollard JR, et al. (2012) The novel ATR inhibitor VE-821 increases sensitivity of pancreatic cancer cells to radiation and chemotherapy. Cancer BiolTher 13: 1072-1081.

24. Qian DB, Zhang XL, Zeng JM, Le Blanc YH, Guo, et al. (2014) Inhibition of human positive cofactor 4 radiosensitizes human esophageal squmaous cell carcinoma cells by suppressing XLF-mediated nonhomologous end joining Cell Death Dis 5: e1461.

25. Chang LPH, Graham J, Hao J, Ni J, Bucci, et al. (2014) PI3K/Akt/mTOR pathway inhibitors enhance radiosensitivity in radioresistant prostate cancer cells through inducing apoptosis, reducing autophagy, suppressing NHEJ and HR repair pathways. Cell Death Dis. 5: e1437.
26. Facchino S, Abdouh M, Chatoo W, Bernier G (2010) BMI1 confers radioresistance to normal and cancerous neural stem cells through recruitment of the DNA damage response machinery. J Neurosci 30: 10096-10111.

27. Ogiwara H, Ui A, Otsuka A, Satoh H, Yokomi I, et al. (2011) Histone acetylation by CBP and p300 at double-strand break sites facilitates SWI/SNF chromatin remodeling and the recruitment of non-homologous end joining factors. Oncogene 30: 2135-2146.

28. Beskow C, Skikuniene J, Holgersson A, Nilsson B, Lewensohn R, et al. (2009) Radioresistant cervical cancer shows upregulation of the NHEJ proteins DNAPKcs, Ku70 and Ku86. Br J Cancer 101: 816-821.

29. Shintani S, Mihara M, Li C, Nakahara Y, Hino S, et al. (2003) Up-regulation of DNA-dependent protein kinase correlates with radiation resistance in oral squamous cell carcinoma. Cancer Sci 94: 894-900.

30. Kozomara A, Griffiths-Jones S (2011) miRBase: integrating micro RNA annotation and deep-sequencing data. Nucleic Acids Res. 39 (Database issue). D152-157.

31. Di Leva G, Garofalo M, Croce CM (2014) MicroRNAs in cancer. Annu Rev Pathol 9: 287-314.

32. Sokol NS (2012) Small temporal RNAs in animal development. CurrOpin Genet Dev 22: 368-373.

33. He L, He X, Lim LP, de Stanchina E, Xuan Z, et al. (2007) A microRNA component of the p53 tumour suppressor network. Nature 447: 1130-1134.

34. Zhang B, Pan X, Cobb GP, Anderson TA (2007) microRNAs as oncogenes and tumor suppressors. DevBiol 302: 1-12.

35. Hayashita Y, Osada H, Tatematsu Y, Yamada H, Yanagisawa K, et al. (2005) A polycistronic microRNA cluster, miR-17-92, is overexpressed in human lung cancers and enhances cell proliferation. Cancer Res 65: 9628-9632.

36. Kandalam MM, Beta M, Maheswari UK, Swaminathan S, Krishnakumar S (2012) Oncogenic microRNA 17-92 cluster is regulated by epithelial cell adhesion molecule and could be a potential therapeutic target in retinoblastoma. Mol Vis 18: $2279-2287$

37. Chang CC, Yang YJ, Li YJ, Chen ST, Lin BR, et al. (2013) MicroRNA-17/20a functions to inhibit cell migration and can be used a prognostic marker in oral squamous cell carcinoma. Oral Oncol 49: 923-931.

38. Wang S, Zhang R, Claret FX, Yang H (2014) Involvement of microRNA-24 and DNA methylation in resistance of nasopharyngeal carcinoma to ionizing radiation. Mol Cancer Ther 13: 3163-3174

39. Li G, Wang Y, Liu Y, Su Z, Liu C, et al. (2014) miR-185-3p regulates nasopharyngeal carcinoma radioresistance by targeting WNT2B in vitro. Cancer Sci 105: 1560-1568.

40. Li G, Liu Y, Su Z, Ren S, Zhu G, et al. (2013) MicroRNA-324-3p regulates nasopharyngeal carcinoma radioresistance by directly targeting WNT2B. Eur J Cancer 49: 2596-2607.

41. Zhang T, Sun Q, Liu T, Chen J, Du S, et al. (2014) MiR-451 increases radiosensitivity of nasopharyngeal carcinoma cells by targeting ras-related protein 14 (RAB14). Tumour Biol 35: 12593-12599.

42. Zhou S, Ye W, Ren J, Shao Q, Qi Y, et al. (2014) MicroRNA-381 increases radiosensitivity in esophageal squamous cell carcinoma. Am J Cancer Res 5 : 267-277.

43. Lynam-Lennon N, Reynolds JV, Marignol L, Sheils OM, Pidgeon GP, et al. (2012) MicroRNA-31 modulates tumour sensitivity to radiation in oesophageal adenocarcinoma. J Mol Med (Berl) 90: 1449-1458.

44. Lan F, Yue X, Ren G, Li H, Ping L, et al. (2015) miR-15a/16 Enhances Radiation Sensitivity of Non-Small Cell Lung Cancer Cells by Targeting the TLR1/NF-î ${ }^{\circ} B$ Signaling Pathway. Int J RadiatOncolBiolPhys 91: 73-81.

45. Zhang HH, Pang M, Dong W, Xin JX, Li YJ, et al. (2014) miR-511 induces the apoptosis of radioresistant lung adenocarcinoma cells by triggering BAX. Oncol Rep 31: 1473-1479.

46. Kang JE, Kim W, Kim KM, Seong H, Youn, et al. (2013) Rhamnetin and cirsilio induce radiosensitization and inhibition of epithelial-mesenchymal transition (EMT) by miR-34a-mediated suppression of Notch-1 expression in non-small cell lung cancer cell lines. J Biol Chem 288: 27343-27357.

47. Zhang P, Wang L, Rodriguez-Aguayo C, Yuan Y, Debeb BG, et al. (2014 miR-205 acts as a tumour radiosensitizer by targeting ZEB1 and Ubc13. Nat 
Commun 5: 5671.

48. Sun Q, Liu T, Yuan Y, Guo Z, Xie G, et al. (2015) MiR-200c inhibits autophagy and enhances radiosensitivity in breast cancer cells by targeting UBQLN1. Int J Cancer 136: 1003-1012.

49. Gasparini P, Lovat F, Fassan M, Casadei L, Cascione L, et al. (2014) Protective role of miR-155 in breast cancer through RAD51 targeting impairs homologous recombination after irradiation. ProcNatIAcadSci U S A 111: 4536-4541.

50. Wang P, Zhang J, Zhang L, Zhu Z, Fan J, et al. (2013) MicroRNA 23b regulates autophagy associated with radioresistance of pancreatic cancer cells. Gastroenterology 145: 1133-1143.

51. Zhang Y, Zheng L, Huang J, Gao F, Lin X, et al. (2014) MiR-124 Radiosensitizes human colorectal cancer cells by targeting PRRX1. PLoS One 9: e93917.

52. Qu C, Liang Z, Huang J, Zhao R, Su C, et al. (2012) MiR-205 determines the radioresistance of human nasopharyngeal carcinoma by directly targeting PTEN. Cell Cycle 11: 785-796.

53. Huang S, Li XQ, Chen X, Che SM, Chen W, et al. (2013) Inhibition of microRNA-21 increases radiosensitivity of esophageal cancer cells through phosphatase and tensin homolog deleted on chromosome 10 activation. Dis Esophagus 26: 823-831.

54. Grosso S, Doyen J, Parks SK, Bertero T, Paye A, et al. (2013) MiR-210 promotes a hypoxic phenotype and increases radioresistance in human lung cancer cell lines. Cell Death Dis 4: e544.

55. Liu ZL, Wang H, Liu J, Wang ZX (2013) MicroRNA-21 (miR-21) expression promotes growth, metastasis, and chemo- or radioresistance in non-small cell lung cancer cells by targeting PTEN. Mol Cell Biochem 372: 35-45.

56. Huang X, Taeb S, Jahangiri S, Emmenegger U, Tran E, et al. (2013) miRNA-95 mediates radioresistance in tumors by targeting the sphingolipid phosphatase SGPP1. Cancer Res 73: 6972-6986.

57. Deng J, Lei W, Fu JC, Zhang L, Li JH, et al. (2014) Targeting miR-21 enhances the sensitivity of human colon cancer HT-29 cells to chemoradiotherapy in vitro. BiochemBiophys Res Commun 443: 789-795.

58. Ren J, Chu Y, Ma H, Zhang Y, Zhang X, et al. (2014) Epigenetic interventions increase the radiation sensitivity of cancer cells. Curr Pharm Des 20: 18571865.

59. Kim JS, Kim SY, Lee M, Kim SH, Kim SM, et al. (2015) Radioresistance in a human laryngeal squamous cell carcinoma cell line is associated with DNA methylation changes and topoisomerase II Î̀. Cancer BiolTher 16: 558-566.

60. Huang KH, Huang SF, Chen IH, Liao CT, Wang HM, et al. (2009) Methylation of RASSF1A, RASSF2A, and HIN-1 is associated with poor outcome after radiotherapy, but not surgery, in oral squamous cell carcinoma. Clin Cancer Res 15: 4174-4180.

61. Zielske SP (2015) Epigenetic DNA methylation in radiation biology: on the field or on the sidelines? J Cell Biochem 116: 212-217.

62. Bian EB, Li J, He XJ, Zong G, Jiang T, et al. (2014) Epigenetic modification in gliomas: role of the histone methyltransferase EZH2. Expert OpinTher Targets 18: $1197-1206$

63. Zelic R, Fiano V, Grasso C, Zugna D, Pettersson A, et al. (2015) Global DNA hypomethylation in prostate cancer development and progression: a systematic review. Prostate Cancer Prostatic Dis 18: 1-12.

64. Day TK, Bianco-Miotto T (2013) Common gene pathways and families altered by DNA methylation in breast and prostate cancers. EndocrRelat Cancer 20: R215-232.

65. Nagarajan RP, Costello JF (2009) Epigenetic mechanisms in glioblastoma multiforme. Semin Cancer Biol 19: 188-197.

66. Barrow TM, Michels KB (2014) Epigenetic epidemiology of cancer BiochemBiophys Res Commun 455: 70-83.

67. Raggi C, Invernizzi P (2013) Methylation and liver cancer. Clin Res HepatolGastroenterol 37: 564-571.

68. Kim EH, Park AK, Dong SM, Ahn JH, Park WY (2010) Global analysis of CpG methylation reveals epigenetic control of the radiosensitivity in lung cancer cell lines. Oncogene 29: 4725-4731.

69. Greer EL, Shi Y (2012) Histone methylation: a dynamic mark in health, disease and inheritance. Nat Rev Genet 13: 343-357.
70. Kim SH, Joshi K, Ezhilarasan R, Myers TR, Siu J, et al. (2015) EZH2 protects glioma stem cells from radiation-induced cell death in a MELK/FOXM1dependent manner. Stem Cell Reports 4: 226-238.

71. Sato T, Kaneda A, Tsuji S, Isagawa T, Yamamoto S, et al. (2013) PRC2 overexpression and PRC2-target gene repression relating to poorer prognosis in small cell lung cancer. Sci Rep 3: 1911.

72. Deb G, Thakur VS, Gupta S (2013) Multifaceted role of EZH2 in breast and prostate tumorigenesis: epigenetics and beyond. Epigenetics 8: 464-476.

73. McCabe MT, Ott HM, Ganji G, Korenchuk S, Thompson C, et al. (2012) EZH2 inhibition as a therapeutic strategy for lymphoma with EZH2-activating mutations. Nature 492: 108-112.

74. He LJ, Cai MY, Xu GL, Li JJ, Weng ZJ, et al. (2012) Prognostic significance of overexpression of $\mathrm{EZH} 2$ and $\mathrm{H} 3 \mathrm{k} 27 \mathrm{me} 3$ proteins in gastric cancer. Asian Pac J Cancer Prev 13: 3173-3178.

75. Zheng F, Liao YJ, Cai MY, Liu YH, Liu TH, et al. (2012) The putative tumour suppressor microRNA-124 modulates hepatocellular carcinoma cell aggressiveness by repressing ROCK2 and EZH2. Gut 61: 278-289.

76. Cao W, Feng Z, Cui Z, Zhang C, Sun Z, et al. (2012) Up-regulation of enhancer of zeste homolog 2 is associated positively with cyclin D1 overexpression and poor clinical outcome in head and neck squamous cell carcinoma. Cancer 118: 2858-2871.

77. Parbin S, Kar S, Shilpi A, Sengupta D, Deb M, et al. (2014) Histone deacetylases: a saga of perturbed acetylation homeostasis in cancer. $\mathrm{J}$ HistochemCytochem 62: 11-33.

78. Zhang L, Liu Z, Ma W, Wang B (2013) The landscape of histone acetylation involved in epithelial-mesenchymal transition in lung cancer. J Cancer Res Ther 9 Suppl 2: S86-91.

79. Mueller S, Yang X, Sottero TL, Gragg A, Prasad G, et al. (2011) Cooperation of the HDAC inhibitor vorinostat and radiation in metastatic neuroblastoma: efficacy and underlying mechanisms. Cancer Lett 306: 223-229.

80. Lee EQ, Puduvalli VK, Reid JM, Kuhn JG, Lamborn KR, et al. (2012) Phase I study of vorinostat in combination with temozolomide in patients with high-grade gliomas: North American Brain Tumor Consortium Study 04-03. Clin Cancer Res 18: $6032-6039$.

81. Ree AH, Dueland S, Folkvord KH, Hole T, Seierstad et al. (2010) Vorinostat, a histone deacetylase inhibitor, combined with pelvic palliative radiotherapy for gastrointestinal carcinoma: the Pelvic Radiation and Vorinostat (PRAVO) phase 1 study. Lancet Oncol 11: 459-464.

82. Clarke MF, Dick JE, Dirks PB, Eaves CJ, Jamieson CH, et al. (2006) Cancer stem cells--perspectives on current status and future directions: AACR Workshop on cancer stem cells. Cancer Res. 66: 9339-9344.

83. Rycaj K, Tang DG (2014) Cancer stem cells and radioresistance. Int J RadiatBiol 90: 615-621.

84. Peitzsch C, Kurth I, Kunz-Schughart L, Baumann M, Dubrovska A (2013) Discovery of the cancer stem cell related determinants of radioresistance. RadiotherOncol 108: 378-387.

85. Yang YP, Chang YL, Huang PI, Chiou GY, Tseng LM, et al. (2012) Resveratro suppresses tumorigenicity and enhances radiosensitivity in primary glioblastoma tumor initiating cells by inhibiting the STAT3 axis. J Cell Physiol. 227: 976-993.

86. Chen YW, Chen KH, Huang PI, Chen YC, Chiou GY, et al. (2010) Cucurbitacin I suppressed stem-like property and enhanced radiation-induced apoptosis in head and neck squamous carcinoma--derived CD44(+)ALDH1(+) cells. Mol Cancer Ther 9: 2879-2892.

87. Desai A, Webb B, Gerson SL (2014) CD133+ cells contribute to radioresistance via altered regulation of DNA repair genes in human lung cancer cells. RadiotherOncol 110: 538-545.

88. Wang WJ, Wu SP, Liu JB, Shi YS, Huang X, et al. (2013) MYC regulation of CHK1 and CHK2 promotes radioresistance in a stem cell-like population of nasopharyngeal carcinoma cells. Cancer Res 73: 1219-1231.

89. Chang L, Graham PH, Hao J, Ni J, Bucci J, et al. (2013) Acquisition of epithelialmesenchymal transition and cancer stem cell phenotypes is associated with activation of the $\mathrm{PI} 3 \mathrm{~K} / \mathrm{Akt} / \mathrm{mTOR}$ pathway in prostate cancer radioresistance. Cell Death Dis 4: e875.

90. Moncharmont C, Levy A, Gilormini M, Bertrand G, Chargari C, et al. (2012) Targeting a cornerstone of radiation resistance: cancer stem cell. Cancer Lett 
Citation: Wu TS, Lin BR, Chang HH, Chang CC (2015) Radio Resistance Mechanisms of Cancers: An Overview and Future Perspectives. Biol Med S2: 002. doi: 10.4172/0974-8369.S2-003

Page 7 of 7

322: $139-147$.

91. Hardee ME, Marciscano AE, Medina-Ramirez CM, Zagzag DA Narayana, et al. (2012) Resistance of glioblastoma-initiating cells to radiation mediated by the tumor microenvironment can be abolished by inhibiting transforming growth factor-beta. Cancer Res. 72: 4119-4129.

92. Mannino M, Chalmers AJ (2011) Radioresistance of glioma stem cells: intrinsic characteristic or property of the 'microenvironment-stem cell unit'? MolOncol 5: 374-386.
93. Diehn M, Cho RW, Lobo NA, Kalisky T, Dorie MJ, et al. (2009) Association of reactive oxygen species levels and radioresistance in cancer stem cells. Nature 458: 780-783.

94. Lagadec C, Dekmezian C, Bauché L, Pajonk F (2012) Oxygen levels do not determine radiation survival of breast cancer stem cells. PLoS One 7: e34545. 